\title{
O ENCONTRO COM O CRACK: INICIO, TEMPO, QUANTIDADE DIÁRIA E FORMAS DE USO
}

\author{
Suelen Cardoso Leite ${ }^{I}$ \\ Michele Mandagará de Oliveira ${ }^{2}$ \\ Vania Dias Cruz
}

O objetivo desta pesquisa foi conhecer as trajetórias de uso, assim como o padrão de consumo da substância entre pessoas que consomem crack. Trata-se de um estudo descritivo-exploratório com abordagem qualitativa, realizado por meio de entrevista semiestruturada, com 14 pessoas acompanhadas pela Estratégia de Redução de Danos da cidade de Pelotas/RS. Os resultados apontam que a maioria dos usuários teve o primeiro contato com drogas ilícitas utilizando a maconha e outras formas de administração da cocaína até elegerem o crack como droga de escolha. Embora o uso de crack seja de forma compulsiva há aqueles que conseguem fazer um uso controlado da substância.

Descritores: Usuários de Drogas; Cocaína Crack; Transtornos Relacionados ao uso de Substâncias.

\footnotetext{
${ }^{1} \mathrm{MSc}$.

2 PhD, Professor Adjunto, Universidade Federal de Pelotas, Pelotas, RS, Brasil.

${ }^{3}$ Doutoranda, Universidade Federal do Rio Grande, Rio Grande, RS, Brasil.
} 


\section{ENCOUNTERS WITH CRACK: BEGINNING, LENGTH OF USE, DAILY QUANTITY AND FORM OF USE}

The aim of this study was to discover trajectories of use as well as consumption patterns among those who use crack. This is a descriptive-exploratory study with a qualitative approach, conducted with 14 individuals monitored by the Reduced Harm Strategy in the city of Pelotas/RS, using a semi-structured interview. The results indicate that the majority of users' first contact with illegal drugs was with marihuana and other forms of cocaine, before choosing crack as their drug of choice. Although crack use is compulsive, there are those who manage to control their use of substance.

Descriptors: Drug Users; Crack Cocaine; Substance-Related Disorders.

\section{ENCUENTRO CON EL CRACK: INICIO, TIEMPO, CANTIDAD DIARIA Y FORMAS DE USO}

El objetivo de esta investigación fue conocer las trayectorias de uso, así como el patrón de consumo de la sustancia entre consumidores de crack. Se trata de un estudio descriptivoexploratorio con enfoque cualitativo, realizado por medio de entrevista semiestructurada, con 14 personas, acompañadas por la Estrategia de Reducción de Daños, realizada en la ciudad de Pelotas, estado Rio Grande do Sur. Los resultados apuntan que la mayoría de usuarios tuvo su primer contacto con la drogas ilícitas utilizando mariguana y otras formas de administración de la cocaína hasta que eligieron el crack como su droga personal . Aunque el crack genere uso compulsivo, algunas personal consiguen hacer un uso controlado de la sustancia.

Descriptores: Consumidores de Drogas; Cocaina Crack; Trastornos Relacionados con Sustancias.

\section{Introdução}

Uma das problemáticas que vem chamando a atenção, tanto do poder público quanto dos órgãos de saúde e da sociedade em geral, é o crescimento do consumo de drogas psicotrópicas, inclusive o uso abusivo do crack.

De acordo com literatura o crack surgiu em bairros pobres dos Estados Unidos na década de 1980, atraindo principalmente jovens e usuários de cocaína injetável que descobriram na cocaína fumável uma alternativa com efeitos igualmente intensos e de baixo custo e ainda, na compreensão deles, sem risco de contaminação pelo vírus HIV, tornando assim o produto que era considerado o champanhe das drogas acessível às camadas mais pobre ${ }^{(1)}$.

No Brasil, o primeiro relato do uso da droga foi na cidade de São Paulo em 1989, dados esses que circulavam em revistas e jornais obtidos por meio de relatórios policiais das primeiras apreensões da $\operatorname{droga}^{(2)}$.

Em virtude dos efeitos estimulantes e prazerosos, aliados aos baixos custos da comercialização ilegal, o crack rapidamente se espalhou pelo território brasileiro, nas mais diferentes classes sociais, podendo ser percebido no cotidiano como um grave problema público que apresenta proporções ainda pouco conhecidas e de grande impacto familiar e social ${ }^{(3)}$. 
Resultados do último levantamento domiciliar sobre drogas psicotrópicas no Brasil apontam que o uso da cocaína na vida corresponde a $2,9 \%$, enquanto o uso do crack representa menos de $1 \%$ e que o consumo dessa substância vem crescendo progressivamente entre crianças e adolescentes moradores de rua, principalmente nas regiões Sul e Sudeste do Brasil ${ }^{(4)}$.

Embora o crack não figure entre as drogas ilícitas mais consumidas no Brasil, colocam o padrão compulsivo e os problemas decorrentes do consumo da droga como um grande problema de saúde pública ${ }^{(5)}$.

Além disso, o crescimento do consumo e dos problemas relacionados ao uso do crack constitui, atualmente, um grande desafio para a implementação de uma política de atenção aos problemas com drogas no Brasil. Este desafio exige respostas eficazes do governo e da sociedade, na construção de um programa de ações integradas, que inclua práticas relacionadas à promoção da saúde ${ }^{(6)}$.

Dessa forma este trabalho tem por objetivo conhecer as trajetórias de uso e os padrões de consumo entre pessoas que fazem uso de crack na cidade Pelotas/RS.

\section{Metodologia}

O presente estudo é parte integrante da pesquisa "Perfil dos Usuários de Crack e padrões de uso", financiada pelo Conselho Nacional de Desenvolvimento Científico e Tecnológico, Edital MCT/CNPq 41/2010. Trata-se de um estudo descritivo, exploratório de abordagem qualitativa.

Participaram do estudo 14 pessoas que faziam uso de crack, acompanhadas pela Estratégia de Redução de Danos (ERD) da cidade de Pelotas/RS e que foram indicadas pelos Agentes Redutores de Danos (ARDs), considerando os seguintes critérios de inclusão: ser usuário de crack acompanhado pela ERD, maior de 18 anos e permitir o uso de gravador no momento da entrevista.

A coleta de dados foi realizada no mês de janeiro de 2012 durante o trabalho de campo dos ARDs nos diferentes bairros do município no contexto em que usuários estão inseridos, ou seja, em locais de uso, suas residências, e no local de trabalho (guardadores de carro), no centro da cidade, tendo cada entrevista duração média de 45 minutos.

Não houve contato prévio ou agendamento com os participantes e o objetivo do estudo foi explicado no momento da abordagem para participação na pesquisa. A seleção dos usuários ocorreu de forma intencional, de acordo com quem se encontrava nos domicílios, cenas de uso e nos diferentes locais de atuação dos ARDs.

Os dados foram obtidos por meio de entrevista semiestruturada que foram gravadas, transcritas na integra e posteriormente analisadas de acordo com as etapas da análise de conteúdo, na modalidade análise temática ${ }^{(7)}$. Assim, os dados foram analisados em três fases distintas: pré-análise, exploração do material e tratamento dos dados obtidos e interpretação.

Para garantir o anonimato, os sujeitos foram identificados por nome de pedras preciosas acrescido da inicial do sexo e da idade. A pesquisa foi aprovada pelo Comitê de Ética em Pesquisa da Faculdade de Enfermagem da Universidade Federal de Pelotas, com parecer favorável $n^{\circ}$ 301/2011 e obedeceu aos princípios éticos da Resolução 196/96 do Conselho Nacional de Saúde que trata das pesquisas envolvendo seres humanos $^{(8)}$.

\section{Resultados e Discussão}

No que se refere aos aspectos sociodemográficos do grupo estudado predominaram usuários de crack adultos jovens, com prevalência na faixa etária dos 25 aos 35 anos de idade, solteiros, com escolaridade fundamental ou média, sem ocupação regular. Dados semelhantes ao que é referido pela literatura: solteiro, com baixa escolaridade e idade entre 18 e 35 anos e sem vínculos empregatícios formais ${ }^{(9-10)}$.

Em relação às características ocupacionais, a grande maioria exercia atividades informais, dentre as profissões as mais citadas foram de faxineira, e guardador de carro. O envolvimento com o tráfico de drogas e prostituição também emergiu nas falas como forma de obtenção de renda.

Eu faço de tudo um pouco, faço limpeza, sou manicure, faço bicos (Rubi F31).

[...] depende do dia, faxina, programa, eu me viro, depende do dia, da hora e do lugar (Ágata F25). 
A evasão escolar foi observada em quase todos os entrevistados. O baixo nível educacional pode implicar, entre outros aspectos, menor inserção no mercado formal de trabalho, menor disponibilidade financeira, consequentemente, maior vulnerabilidade social e também pode estar associada ao inicio precoce do uso de drogas.

Ademais, os poucos anos de estudo e a falta de experiência em qualquer atividade de trabalho fazem os trabalhos informais continuarem sendo, ainda, o meio de sobrevivência da maioria dos usuários de $\operatorname{crack}^{(11)}$. Característica essa corroborada com o presente trabalho, no qual apontou que a maioria dos entrevistados encontrava-se em situação autônoma.

O consumo de drogas está presente na sociedade desde os primórdios da humanidade e na maioria dos casos de dependência de crack existe uma escalada entre o consumo de drogas até o primeiro contato com o crack.

A primeira droga ilícita utilizada costuma ser a maconha e após o uso desta primeira droga psicoativa, os usuários com o passar do tempo, motivados pela curiosidade de descobrir novos prazeres, acabam experimentando outras drogas como cocaína aspirada e injetada até chegarem ao crack como última droga consumida ${ }^{(12)}$.

Percebe-se nos depoimentos, que o uso da maconha e da cocaína fazia parte das práticas cotidianas da maioria dos entrevistados. Essas informações podem ser observadas nos discursos a seguir:

[...] história de maconha e cocaína, ai ele chegou com o crack e nós experimentamos [...] (Rubi F31)

[...] desde 2003 que eu sou drogada no crack [...] comecei usando cocaina tomava nas veias [...] usei tudo que é porcaria, maconha tudo [...] (Amazonita F51)

[...] só cocaína e maconha ai chegou o crack e eu resolvi experimentar [...] (Esmeralda F35)

$\mathrm{Na}$ construção dessas trajetórias pôde-se evidenciar que dos 14 entrevistados apenas uma usuária teve sua primeira experiência de uso de drogas com o crack. Os demais começaram o uso de substâncias psicoativas principalmente com maconha, seguido da cocaína tanto aspirada quanto injetável.

[...] a minha droga é só o crack eu nunca fumei maconha nem cheirei [...] (Ametista F19)

O tempo de uso de crack entre os sujeitos variou de 2 a 15 anos, e somente dois usuários consumiam crack há menos de cinco anos. A idade média de início do consumo da droga foi 26,4 anos, dados semelhantes àqueles encontrados em outro estudo com pessoas que faziam uso de $\operatorname{crack}^{(13)}$ em que a média de início do consumo de crack foi de 23,87 anos. Tal fato pode-se dar devido à idade dos participantes do estudo, visto que 13 deles apresentam idade igual ou superior a 25 anos e o crack ser considerando uma droga ainda recente.

\section{[...] Comecei a usar com 40 anos. (Turquesa F42)}

Tinha 19 anos [...] (Ônix F28)

[...] ah faz mais de 10 anos, faz anos, foi quando chegou aqui [...] (Citrino M42)

Devido às suas especificidades psicofarmacológicas, o padrão predominante de uso de $\mathrm{cra}$ $c k$ descrito nos estudos com usuários da droga é o de tipo Binge, ou seja, o usuário tende a usá-lo por horas ou mesmo dias a fio, alternando dias sem uso, os quais podem durar até mesmo meses inteiros, com episódios de uso intenso ${ }^{(1,14)}$.

Dentre os padrões de consumo identificados, o uso compulsivo foi o mais relatado entre os participantes da pesquisa, constituindo um consumo diário de crack podendo estender-se ao longo dia cessando apenas quando o usuário atingia o esgotamento físico, psíquico ou financeiro.

[...] eu durmo só depois que cansa mesmo, depois que eu não consigo nem comigo mesma [...] quando eu uso é o dia inteiro e a noite também [...] (Ágata F25)

[...] uso todos os dias, eu uso umas 30,40 pedras por dia, uso toda hora [...] (Diamante F30)

Falas como essas foram repetidamente manifestadas por outros entrevistados, destacando essa característica de padrão compulsivo de consumo, esboçando um aparente consenso quanto à dificuldade em manter um uso esporádico ou controlar a quantidade utilizada, atribuindo à fissura papel fundamental na manutenção da dependência, como responsável ou dificultando o abandono do uso da droga.

[...] muito dificilmente eu consigo passar 2, 3 dias sem usar [...] mas o normal é todos os dias eu usar [...] eu acordo de manhã usando e vou dormir usando [...] (Quartzo M31).

Para a grande maioria dos entrevistados, o momento em que foi evidenciado o uso diário do crack, ocorreu pouco tempo depois de ser incorporado às práticas de uso. Esse período de incorporação do crack ao cotidiano, com a intensificação do uso contribuiu para a desestabilização 
do próprio cotidiano e das relações que giravam em torno dele.

O uso descontrolado de crack também evidenciado na quantidade diária de consumo da droga chamou a atenção pelo fato de a substância ser vendida não só em pequenas pedras no valor de cinco reais como descrito em muitos estudos, mas também por gramas segundo as narrativas dos entrevistados.

A compra do crack por peso parece ser restrita àqueles usuários com melhor poder aquisitivo e quando se consegue uma boa quantia em dinheiro a compra do crack é feita em grama. Conforme o relato de Safira, que revelou que a maior quantia em dinheiro gasta com o uso do crack foi de 50 reais, adquirido de um trabalho como diarista que realizou.

[...] um dia que eu ganhei 27 vales [...] deu 48 e uns quebrado o vale, e eu peguei duas gramas [...] só que a gente fica devendo né [...] (Safira F48).

O crack vendido em gramas denota uma grande quantidade da droga, pois, segundo as informações dos sujeitos, um grama corresponde a cerca de oito pedras de crack revelando em suas falas que o uso por peso é bastante abusivo. Tal informação é ilustrada nos seguintes discursos:

[...] Olha mais de uma grama é [...] uma grama deve dar umas 8 pedras, eu devo usar umas 15 pedras [...] (Rubi F31)

Não dá nem pra contar [...] é gramas e gramas [...] (Amazonita F51)

Em média, os usuários da droga utilizam semanalmente 68 pedras de rrack $^{(15)}$. Calculandose os valores de consumo dos usuários deste estudo, a prática representa uma média de dez pedras diárias e n,o caso dos usuários que utilizam a droga todos os dias, esse valor pode chegar a 300 pedras no mês, contabilizando um gasto de aproximadamente 1.500 reais mensais em pedras de crack.

Assim como em outros trabalhos envolvendo usuários de crack, a prostituição e a associação com o tráfico também perpetuaram neste estudo $^{(1,9)}$. As mulheres que revelaram se prostituir o faz para manter o vício no crack, referindo gastar tudo o que ganham com a venda do corpo no uso da droga.

[...] porque eu faço pra usar [...] fiz programa e ganhei 250 e fui pra casa do patrão e fumei tudo [...] (Ágata F25).

Apenas dois usuários admitiram práticas ilícitas como o tráfico de drogas e pequenos furtos para manterem o vício, os demais referiram atividades informais como guardador de carros, faxinas e até mesmo pedir dinheiro na rua ou a pessoas as quais mantém um contato mais próximo.

Uma vez que o crack adquiriu lugar de extrema importância na vida do indivíduo, na urgência em consumi-lo são realizadas atividades que colocam em risco sua integridade moral e física, pois o que está em foco é o uso de mais crack.

Para a pessoa em fissura, perder a família, descuidar do próprio corpo, gastar altas quantias como Topázio que gastou uma grande quantia em dinheiro em um único dia de uso intenso, nada parece tão ruim quanto não usar crack.

[...] mil reais [...] foi de um trabalho que eu tinha pra receber [...] Ah foi muito, muito crack [...] usei em 24hs (Topázio M37).

Embora o uso compulsivo seja o mais relatado, foi identificado entre os participantes do estudo usuários que desenvolvem uma série de estratégias para regular o uso da substância na sua vida sempre corrida buscando evitar que o consumo da substância interfira nas suas atividades de trabalho, desenvolvendo um tempo e lugar reservado para o consumo.

Esse tipo de usuário faz um uso que Norman Zimberg, um dos pioneiros a descrever o padrão de consumo de drogas, denomina uso controlado, que se caracteriza por um uso racional, não diário em que o indivíduo consegue manter suas atividades sociais preexistentes, sem que sua rotina circule em torno do uso do $\mathrm{crack}^{(16)}$.

[...] todos os dias não, se me bate vontade, dai como hoje eu não quero fumar, depende do dia (Ametista F19).

[...] comi, trabalhei [...] foi só o que eu fiz, eu não uso durante o dia só durante a noite [...] (Berilo M25).

$\mathrm{O}$ uso do crack se dá geralmente por meio de cachimbos artesanais que são confeccionados com vários tipos de materiais como latas de alumínio, tampas de garrafa pet entre outros.

Os insumos utilizados podem ser diversos, mas a forma de colocar a pedra em combustão é sempre a mesma, colocando-se a cinza de cigarro no local onde será queimado o crack em cima a pedra, que é acesa, sendo possível assim aspirar a fumaça ${ }^{(17)}$.

Considerando que a lata é o principal material utilizado para fumar a droga, o contato repetido com o alumínio aquecido pode causar 
queimaduras na língua, lábios, rosto e dedos e, uma vez compartilhado entre os usuários, pode ser importante fator de risco para contaminação por doenças infectocontagiosas ${ }^{(6)}$.

Observa-se nas falas que a maior parte dos sujeitos do estudo fazem o uso do crack em cachimbos improvisados com tampa de garrafa pet, alumínio e antena de televisão e apenas uma usuária referiu fazer o uso da substância na lata de alumínio.

[...] meu cachimbo é de tampinha [...] (Ágata F25)

[...] tenho cachimbo [...] aqui tem um caninho de metal, uma tampa de garrafa PVC e aluminio [...] (Rubi F3).

[...] a gente faz o cachimbo de tampa de PVC [...] (Ônix F28).

[...] tampa de PVC mais antena [...] (Diamante F30).

Consumir crack na lata pode ser considerado mais prejudicial porque geralmente são coletadas na rua ou no lixo e podem estar contaminadas com diferentes agentes infecciosos; em contrapartida mais da metade dos participantes que referiu ter um cachimbo artesanal revelou compartilhá-lo com outras pessoas no momento do uso, revelando-se também como fator predisponente para a transmissão de doenças contagiosas.

O uso combinado de outras drogas associadas ao crack foi unânime entre os sujeitos do estudo, as drogas utilizadas eram o álcool, o tabaco e a maconha. Todos os usuários referiram o uso do tabaco quando do uso do crack, tal fato pode ser devido à necessidade do uso das cinzas do cigarro para queimar a pedra e assim ser fumada.

$\mathrm{O}$ crack pode ser fumado de diferentes maneiras, em cachimbos ou em forma de cigarros, o chamado pítico, que é pedra de crack colocada dentro de cigarros de maconha ${ }^{(17)}$. Dos 14 entrevistados, oito mencionaram usar maconha associada ao crack, seja na forma de pítico ou na forma de baseado após consumirem o crack.

O uso da maconha associado ao crack parece ter surgido como alternativa de atenuar os efeitos negativos advindos do uso da droga, como a fissura e outros efeitos ansiogênicos. Essa associação permite que o usuário consiga descontinuar o uso e retorne suas atividades habituais, servindo como um importante regulador do consumo de $\operatorname{crack}^{(14)}$.

Ah, maconha depois que não tem mais o corre do crack, ai pra relaxar, ai pra comer ai eu uso maconha. (Safira F48).
O álcool também aparece como uma droga associada ao crack nas narrativas dos sujeitos e o seu uso por usuários de crack tem sido uma das estratégias encontradas para reduzir os efeitos paranoides, capaz de amenizar o medo e a ansiedade $^{(14)}$. O álcool é empregado também como um calmante para a fissura; no entanto, pode servir de gatilho para alguns usuários estimulando o indivíduo ao consumo drogas.

[...] sempre acompanhado de cerveja, sempre de cerveja [...] (Berilo M25).

[...] tomo cachaça [...] (Ônix F28).

Ainda que o uso do álcool tenha sido declarado por muito dos usuários como frequente, principalmente quando usam o crack, apenas duas entrevistadas relataram uso problemático com essa substância, revelando que nem mesmo o crack faz que saiam do controle como o uso da bebida alcoólica.

[...] o crack não faz eu perder as estribeiras mas a cachaça $\operatorname{sim}[\ldots]$ (Ágata F25).

[...] eu tenho mais problema com a bebida do que com a droga com a bebida eu saio do controle geral [...] (Rubi F31).

O uso do álcool em combinação com o uso da cocaína (seja qual for a forma de administração) é considerado a associação mais frequente de uso de drogas. Essa combinação resulta na formação de um novo composto denominado cocaetileno cujos efeitos fisiológicos são muito semelhantes ao da cocaína (potencialização da euforia), porém com maior toxicidade cardíaca e hepática ${ }^{(18)}$.

O consumo associado dessas duas drogas gera uma maior perda do controle do consumo, problemas sociais e condutas violentas que levam a comportamentos de risco, sendo a base de quadros clínicos de maior gravidade observados ${ }^{(18)}$.

Embora os usuários quando no uso da droga se expõem a situações de risco, percebe-se que muitos já conseguem desenvolver estratégias para minimizar os danos decorrentes do uso da substância. Alguns usuários relatam não compartilhar o instrumento de uso das substâncias, outros delimitam o uso a determinado período do dia e há ainda aqueles que só utilizam a droga somente após se alimentar.

\section{Considerações Finais}

Foi possível evidenciar que para quase todos os usuários o encontro com o crack aconteceu 
após terem iniciado suas carreiras de uso de drogas com a maconha, passando pelas diferentes formas de administração da cocaína até chegarem ao crack como última droga de escolha.

O padrão de uso compulsivo foi o mais relatado pelos entrevistados, caracterizado pelo uso diário em que o cotidiano gira em torno do consumo de crack. Diante de inúmeras narrativas, descrever essa experiência é descrever a compulsão e falta de controle diante da droga em que a liberdade de escolha desaparece e dá lugar ao consumo de cada vez mais crack por mais que o corpo aponte para o insuportável.

Em contrapartida, há aqueles que estão desenvolvendo estratégias próprias de regulação do consumo da droga, buscando em outras substâncias psicoativas como o álcool e a maconha, amenizar os efeitos do crack e reduzir os danos decorrentes do consumo desta substância.

Diante disso, percebe-se que, dependendo da finalidade do consumo, se dão os efeitos das drogas, ou seja, há outro caminho para se pensar e discutir que não se detém somente no fármaco como responsável pelos comportamentos dos indivíduos, mas sim no sujeito inserido no seu contexto social, sob a perspectiva de fatores psicológicos, sociológicos e culturais que moldam motivações, experiências e comportamentos.

Outro fator importante na vida desses usuários de crack foi o envolvimento com o tráfico e prostituição, por não conseguirem controlar o uso intenso passam a praticar pequenos furtos e trocar sexo por dinheiro para aquisição do crack. Atividades ilícitas de rápido retorno financeiro que acaba por gerar, além de um comprometimento moral e social um grande risco para suas vidas.

Percebe-se também a frequente associação do crack com outros tipos de drogas, que pode vir a agravar o estado atual de dependência e gerar uma codependência; no entanto, ressalta-se que a combinação de outras drogas principalmente da maconha visa atenuar a fissura causada pelo crack, servindo como uma importante estratégia de redução de danos.

Diante do exposto, é perceptível a necessidade de se preocupar não somente com o uso abusivo de crack, mas também com as vulnerabilidades geradas por esse uso, pois o problema não está somente nas drogas e sim nas pessoas e em suas condições objetivas e subjetivas de existência, o que justificam por si só, a importância e emergência de intervenções, bem como a ampliação de conhecimentos nesta área.

\section{Referências}

1. Oliveira LG, Nappo SA. Caracterização da cultura de crack na cidade de São Paulo: padrão de uso controlado. Rev Saúde Pública. 2008;42(4):664-71.

2. Raupp L, Adorno RCF. Jovens em situação de rua e usos de crack: um estudo etnográfico em duas cidades. Rev Bras Adolesc Conflitual. 2011;(4):52-67.

3. Kessler F, Pechansky F. Uma visão psiquiátrica sobre o fenômeno do crack na atualidade. Rev Psiquiatr Rio Gd Sul. 2008;30(2):96-8.

4. Carlini EA, Galduroz JCF, Silva AAB, Noto AR, Fonseca AM, Carlini CM, et al. II Levantamento Domiciliar sobre o uso de drogas psicotrópicas no Brasil: estudo envolvendo as 108 maiores cidades do Brasil, 2005. São Paulo: Centro Brasileiro de Informações sobre Drogas Psicotrópicas/ Secretaria Nacional Antidrogas; 2007.

5. Chaves TV, Sanchez ZM, Ribeiro LA, Nappo SA. Fissura por crack: comportamentos e estratégias de controle de usuários e ex-usuários. Rev Saúde Pública. 2011;45(6):1168-75.

6. Nonticuri AR. As vivências de adolescentes e jovens com o crack e suas relações com as políticas sociais protetoras neste contexto [dissertação]. Pelotas: Universidade Católica de Pelotas; 2010.

7. Minayo MCS. O desafio do conhecimento: pesquisa qualitativa em saúde. São Paulo: Hucitec; 2010.

8. Ministério da Saúde (BR). Conselho Nacional de Saúde. Comissão Nacional de Ética em Pesquisa. Resolução no 196 de 10 de outubro de 1996: diretrizes e normas regulamentadoras de pesquisa envolvendo seres humanos. Brasília (DF): MS; 1996

9. Oliveira LG, Nappo SA. Crack-cocaine in São Paulo: accessibility, market strategies and ways of use. Rev Psiq Clin. 2008;35(6):212-8.

10. Araujo RB, Pansard M, Boeira BU, Rocha NS. As estratégias de coping para o manejo da fissura de dependentes de crack. Rev HCPA. 2010;30(1):36-42. 
11. Galduróz JC. O Uso de inalantes (solventes) entre estudantes de $1^{\circ}$ e $2^{\circ}$ graus em dez capitais brasileiras [tese]. São Paulo: Universidade Federal de São Paulo; 1993.

12. Sanchez ZVDM, Nappo SA. Seqüência de drogas consumidas por usuários de crack e fatores intervenientes. Rev Saúde Pública. 2002;36(4):420-30.

13. Guimarães C, Santos D, Freitas R, Araújo R. Perfil do usuário de crack e fatores relacionados à criminalidade em unidade de internação para desintoxicação no Hospital Psiquiátrico São Pedro de Porto Alegre (RS). Rev Psiquiatr Rio Gd Sul. 2008;20(2):101-8.

14. Ribeiro LA, Sanchez ZM, Nappo SA. Estratégias desenvolvidas por usuários de crack para lidar com os riscos decorrentes do consumo da droga. J Bras Psiquiatr. 2010;59(3):210-8.

15. Zeni TC, Araújo RB. Relação entre o craving por tabaco e o craving por crack em pacientes internados para desintoxicação. J Bras Psiquiatr. 2011;60(1)28-33.

16. Zinberg N. Drug, Set and Setting, New Haven, Yale University Press; 1984.

17. Domanico A. "Craqueiros e cracados: bem vindo ao mundo dos nóias". Estudo sobre a implementação da estratégia de redução de danos para usuários de crack nos cinco projetos-piloto do Brasil [tese] Bahia: Universidade Federal da Bahia; 2006.

18. Prior NP, Payá JM, Company ES, Piqueres RF, Calvo MC, Barco RR. Transcendencia del cocaetileno en el consumo combinado de etanol y cocaína. Rev Española Drogodependencias. 2006;31(3y4):254-70. 